\title{
Big Data, exploração ubíqua e propaganda dirigida: novas facetas da indústria cultural
}

\author{
Deborah Christina Antunes ${ }^{\text {a* }}$ \\ Ari Fernando Maiab \\ aUniversidade Federal do Ceará, Departamento de Psicologia. Sobral, CE, Brasil \\ ${ }^{b}$ Universidade Estadual Paulista Júlio de Mesquita Filho, Departamento de Psicologia. Bauru, SP, Brasil
}

\begin{abstract}
Resumo: A emergência da cultura digital a partir do desenvolvimento de novas tecnologias de informação e comunicação levou a críticas ao conceito de indústria cultural elaborado por Horkheimer e Adorno nos anos 1940, definindo a nova configuração a partir da interatividade, comunicação aberta e maior liberdade entre usuários. Entretanto, a um olhar crítico, a nova configuração se revela mais totalitária que a anterior. Todas as ações dos usuários no ambiente digital geram informações que podem ser compiladas e organizadas de acordo com algoritmos matemáticos, configurando o chamado Big Data; essas informações incluem dados sobre preferências, tendências políticas, gênero e perfis de personalidade, e levam a tentativas de vigilância ubíqua e manipulação por meio de propaganda dirigida, sendo política e economicamente muito mais eficaz do que na era da indústria cultural descrita por Adorno. A atualização da teoria crítica da sociedade implica compreender essa nova configuração, suas pretensões e contradiçõoes. Nesse sentido, este artigo objetiva tanto atualizar o conceito de indústria cultural, denunciando, assim, as novas formas de manipulação, quanto criticar a ideia de que a liberdade é imanente à Cultura Digital, presente em seus defensores.
\end{abstract}

Palavras-chave: indústria cultural, teoria crítica da sociedade, Big Data, cultura digital.

\section{Introdução}

Cena 1: março de 2017. Um pesquisador utiliza seu computador para verificar a existência de um livro, Sociedade do espetáculo de Guy Debord, no catálogo de uma grande livraria física e on-line. Pausa para um café. Minutos depois, ao retornar e entrar em um site de notícias, percebe no menu à direita um reclame: a oferta do livro que buscava, com 30\% de desconto. Cena 2: novembro de 2016. Contrariando as previsões eleitorais, um jornalista anuncia pela TV, em rede mundial, que Donald Trump é o novo presidente dos Estados Unidos da América. Cena 3: junho de 2016, eleitores britânicos votam em favor da saída do Reino Unido da União Europeia. Cena 4: setembro de 2017, João Dória faz uso de cinco programas diferentes para aumentar seu alcance nas redes sociais.

Num olhar apressado, essas quatro cenas podem parecer nada de comum ter entre si. Ocorridas em partes distantes do globo, também parecem remeter a esferas diferentes da vida. O que haveria em comum entre o ato individual de compra e o ato coletivo do voto? O que teria a ver a eleição de um presidente antidemocrático, sexista e xenofóbico, a saída de um país de uma união econômica e política de Estados Europeus, o uso do

\footnotetext{
* Endereço para correspondência: deborahantunes@ufc.br Bolsista Produtividade Funcap 2016-2018 (processo nº BP2-0107-00067. $01.00 / 15)$.
}

Big Data, ${ }^{1,2}$ por um político e empresário brasileiro e a compra de um livro de crítica social numa loja virtual? Talvez nada, se partíssemos do pressuposto de que essas diferentes ações fossem realizadas por sujeitos autônomos e independentes, guiados unicamente por seu entendimento a despeito das determinações do mundo sensível. É o mundo atual, conectado e sustentado por um novo "cimento social", para lembrar uma expressão utilizada por Adorno e Simpson (1986, p. 138), que liga uma cena a outra: o mundo digital coloca-se no cenário desses quatro momentos, com especificidades que nos mostram que a radicalização de um novo modelo de ideologia está em andamento.

Na década de 1940, Adorno escreveu que não havia diferença entre a escolha de um sabonete num supermercado e a escolha de um candidato à presidência

1 Ao longo deste artigo a expressão Big Data será utilizada tanto no singular como no plural. Entendemos que esse uso ambíguo reflete uma característica do próprio objeto em tela; pode-se compreender e lidar com dados massivos garimpados por meio de algoritmos de modo a produzir conhecimento socialmente relevante, e nesse sentido os dados preservam seu caráter múltiplo e aberto, merecendo o tratamento plural. Por outro lado, o uso dos dados massivos por corporações globais tende a se configurar num sistema integrado, tal como já ocorria em alguma medida com a Indústria Cultural, e o artigo no singular particulariza essa tendência a uma ordem totalitária. Eventualmente, em algumas passagens do texto, pode-se questionar se o uso no singular ou no plural está adequado ao momento da discussão, mas a polêmica é bem-vinda e pode ser, entrementes, esclarecedora dos problemas relacionados às tentativas atuais de conceituar o(s) Big Data.

2 Indicamos, para termos específicos em tecnologia que possam oferecer dificuldades ao leitor, a utilização de glossários ou dicionários específicos da área, como o "Dicionário prático de informática" (https://goo.gl/ WZQuaX). 
nos Estados Unidos. Ele fazia referência ao modo como a propaganda nos setores do comércio e da política influenciavam os cidadãos de modo que não deixava espaço para a reflexão crítica sobre suas próprias escolhas, seja no âmbito privado, seja no público. A indústria cultural, ao oferecer um mundo padronizado e um rol de pensamentos estereotipados e em bloco a seus consumidores, os havia privado da possibilidade de exercer uma escolha para além da imitação de padrões dentro de um comportamento de massa; muito embora - é preciso reconhecer - a dominação não fosse exercida sem lacunas. Sete décadas se passaram, e parece que as coisas não estão muito diferentes, exceto pelo grau de refinamento técnico alcançado por um novo ramo da indústria cultural que se vende como "cultura digital", com a pretensão de ser aberta e democrática, radicalizando a crença na individualidade plena. Dessa forma, este artigo busca tanto atualizar o conceito de indústria cultural, denunciando, as novas formas de manipulação, quanto criticar as pretensões de liberdade dos defensores da Cultura Digital.

Individualismo, consumo, dificuldade de aceitação das diferenças são algumas das marcas da Tecnocultura termo usado por Sodré (2010) para caracterizar a nova faceta de uma cultura tecnologicamente mediada. Nela, o autor compreende que há

uma transformação das formas tradicionais de sociabilização, além de uma nova tecnologia perceptiva e mental. Implica, portanto, um novo tipo de relacionamento do indivíduo com referências concretas ou com o que se tem convencionado designar como verdade, ou seja, uma outra condição antropológica. (Sodré, 2010, p. 27)

É, à primeira vista, curioso o interesse do mercado e da política nos Big Data. Contudo, é sempre importante lembrar a vinculação entre essas duas esferas, vinculação esta irremediável na sociedade burguesa. Se o universo da política institucional é o local por excelência de realização das condições para a manutenção do modo de produção da sociedade em voga (Maar, 2006), tal interesse comum não parece tão estranho. Ao contrário, para a manutenção de um dado modelo de sociedade, o desenvolvimento tecnocientífico tem levado às últimas consequências as possibilidades e estratégias de manipulação das massas. Se podemos falar de uma nova condição antropológica, é devido ao refinamento do controle sobre os comportamentos humanos registrados digitalmente por meio de algoritmos criados especificamente para esse fim. A partir de um esquema formalmente delimitado, os programas e aplicativos on-line registram e inteligentemente oferecem aos usuários a repetição de si mesmos; reforçam, com isso, toda uma série de estereótipos e pensamentos padronizados sobre si e sobre o outro, ao tolher o contato com o que não aparece no espelho obscuro de nossas telas. Foi assim que Trump venceu as eleições nos Estados Unidos³: se utilizando dos dados de usuários das redes sociais para dirigir-lhes propagandas mais afeitas aos seus desejos, preconceitos e visões de mundo, e ao mesmo tempo reforçá-los e mantê-los fomentando a bolha da intolerância e do medo.

É urgente, portanto, fazer a crítica dos novos meios digitais de comunicação no âmbito de uma teoria crítica da sociedade que revele a reprodução e a radicalização da barbárie no presente, disfarçada de individualidade e liberdade na sociedade tecnológica. Isso se torna ainda mais urgente quando percebemos que a transformação das condições objetivas que fazem da barbárie e da civilização as duas faces de um mesmo momento histórico pode apenas ser realizada na medida em que são reveladas suas contradições, seus modos de funcionamento e seus efeitos deletérios. A crítica aos novos meios digitais se coloca, assim, como uma crítica política, cujo objetivo está, para além da neutralidade da técnica (pois a denuncia como ideologia), em possibilitar a compreensão do presente para a supressão da barbárie.

\section{Indústria cultural x cultura digital}

Em um texto que discute em que sentido ainda é possível falar em indústria cultural, Hullot-Kentor (2008) argumenta que o conceito tem uma existência paradoxal, pois: "se o conceito não escapa à aparente exaustão das palavras de Adorno e se não resta dúvida de que seu fantasma se foi, ainda assim ele tem uma sobrevida vigorosa" (p. 18). Sua sobrevida e obsolescência estão ligadas ao mesmo fenômeno: à radicalização da sujeição da esfera cultural e à lógica da indústria se soma uma utilização banal e generalizada da expressão "indústria cultural" para designar justamente as possibilidades comerciais ainda em aberto, ou seja, a menção ao conceito já não move o pensamento a partir da chocante menção ao paradoxo da produção industrial de cultura, mas se converteu, ele mesmo, em slogan que paralisa a crítica.

Além disso, de acordo com Antunes em sua palestra Notas para pensar a Indústria Cultural na era digital ${ }^{4}$, pesquisadores marxistas apontam a inadequação do termo devido à sua origem supostamente europeia, justificando, com isso, seu argumento de que ele nada teria a dizer sobre a realidade brasileira ou latinoamericana. No primeiro caso apresentado no parágrafo anterior, como slogan que paralisa a crítica, o termo parece aceito e fixado. Já aqui ocorre uma recusa de

3 No Brasil, um dos primeiros veículos a noticiar tal façanha foi o website especializado em tecnologia da informação Showmetech (https://goo.gl/ voHaBX). No início de 2018, um escândalo envolveu a rede social virtual Facebook e a agência Cambridge Analytica por uma "falha" na segurança dos dados dos usuários da rede e sua venda para a agência britânica de consultoria política que trabalhou tanto nas eleições de Trump, em 2016, quanto durante o plebiscito Brexit, que decidiu sobre a saída do Reino Unido da União Europeia. Sobre o escândalo de 2018, ver: <https://goo. gl/2uV9Vh>; <https://goo.gl/fEkZoD>; e <https://goo.gl/ixEwWX>.

4 Palestra proferida na Universidade do Estado de Santa Catarina (Udesc), em 5 de julho de 2017. 
reconhecimento da importância de se pensar sobre a indústria cultural no Brasil ou mesmo em termos globais. Tal recusa impossibilita um avanço do conhecimento no que concerne a suas novas formas aqui e agora, assim como seus desdobramentos sociais e subjetivos. Outros pesquisadores voltados ao pós-estruturalismo, por sua vez, têm dificuldade em compreender a indústria cultural como um sistema para além de uma mídia específica ou um de seus diversos ramos (TV, cinema, rádio etc.) - muito embora eles estejam atentos às formas como o capitalismo, por intermédio do desenvolvimento tecnológico, controla os corpos e produz subjetividades. Para esses, estamos em um novo tempo, no qual novas mídias foram desenvolvidas e, por isso, o conceito de indústria cultural estaria ultrapassado.

É importante compreender, contudo, que os conceitos não se mantêm idênticos ao longo da história. As transformações na sociedade, assim como as mudanças no pensamento são condições de reelaboração de conceitos em um enlace histórico e social. O termo indústria cultural, que apareceu pela primeira vez em um artigo de Horkheimer (1941, p. 303) no plural, é trabalhado minuciosamente por ele e Adorno no capítulo homônimo da Dialética do esclarecimento, cujo subtítulo "O esclarecimento como mistificação das massas" realiza uma dupla denúncia. Ela é, ao mesmo tempo, fruto do esclarecimento e de todo progresso tecnocientífico por ele fomentado, e amplamente voltada para manter a todos em um estado de falsa consciência necessária para a manutenção de necessidades econômicas. A crítica à indústria cultural é integrada, portanto, à crítica da economia política na medida em que apresenta a esfera da cultura transformada em mercadoria, na qual o consumidor - ao contrário de ser aquele a quem se pretenda de fato agradar - não é sujeito, mas objeto, uma vez que é cercado de produtos cuja função é justamente limitar suas possibilidades de existência. Como apresenta Adorno (1994), à padronização das mercadorias e à racionalização das técnicas de produção somam-se formas individuais de produção calcadas em procedimentos técnicos e na divisão do trabalho, que conferem aos produtos a ilusão de individualidade e que transformam aquilo que poderia ser subversivo na arte em barbárie e opressão repetida.

Se, à época da Dialética do esclarecimento, quando Adorno e Horkheimer (1985) apresentaram o conceito de Indústria Cultural enquanto um sistema, dele faziam parte cinema, rádio, televisão, sistemas urbanos arquitetura etc., hoje, podemos considerar seu alargamento a partir de um avanço tecnológico e digital, cuja função de fomentar a reprodução do vigente via experiências substitutivas, como apontou Maar (2000), representa o nexo entre a indústria cultural da década de 1940 e a indústria cultural atual e suas novas facetas.

Os meios de comunicação digitais têm características bastante específicas que não devem ser negligenciadas. Nesse sentido, é evidente a necessidade de avaliar e considerar os desenvolvimentos tecnológicos no campo da comunicação, que teriam o poder de alçar os usuários das novas máquinas digitais ao nível de consumidores-produtores, superando a suposta passividade dos espectadores da indústria cultural em meados do século $\mathrm{XX}^{5}$. O problema dos aparatos da indústria cultural em meados do século passado, então, seria sua natureza unidirecional. A chamada cultura digital (Costa, 2003) estaria intimamente vinculada a ideias de interatividade, comunicação aberta, interconexão e trocas "livres" de informações e imagens, e isso culminaria necessariamente em "mais liberdade". Essa suposição, que poderia parecer plausível, não resiste a uma análise crítica da configuração que adquire hoje o trânsito das informações, imagens e demais dados na internet. Ao contrário, há hoje uma concentração do controle sobre o fluxo de informações sem precedentes. Para compreendê-la é necessário pensar como se processam atualmente os Big Data - dados massivos -, quem são os operadores desse sistema e com quais fins eles são dirigidos, filtrados e administrados.

Big Data é definido por Mayer-Schönberger e Cukier (2013, p. 13) como "a capacidade da sociedade de aproveitar a informação de formas novas, para obter percepções úteis ou bens e serviços de valor significativo", e se refere a

coisas que podem ser feitas em grande escala, mas não em escala menor, para extrair novas percepções ou criar novas formas de valor, de tal forma que transformam os mercados, as organizações, as relações entre os cidadãos e os governos etc. (Mayer-Schönberger \& Cukier, 2013, p. 17) ${ }^{7}$

Ele indica uma característica da cultura no ambiente digital que coloca em questão a forma em que vivemos e interagimos com o mundo através de um conjunto de aparatos digitais (computadores, telefones móveis, tablets etc.) que envia e capta dados em escala global, e essas informações se configuram num fluxo com volume

5 Aqui, a ideia de passividade diz respeito apenas ao fato de que a interação possível dos consumidores com os produtos da indústria cultural na década de 1940 se restringia a aceitar ou não aquilo que era produzido e apresentado através dos meios de comunicação de massa, como as músicas, filmes, notícias etc. Hoje o consumidor é também um produtor de conteúdos, um trabalhador - ainda que não consciente dessa indústria, na medida em que os meios de comunicação digitais sobrevivem a partir de sua ação e interação na rede. É importante, contudo, não esquecer que em qualquer época, mesmo a aceitação de uma mercadoria depende não de uma passividade completa do sujeito, mas de um esforço na adaptação que não ocorre sem contradições em relação àquilo que seria, de fato, seu interesse no que concerne às possibilidades de liberdade.

6 No original: "la capacidad de la sociedad de aprovechar la información de formas novedosas, para obtener percepciones útiles o bienes y servicios de valor significativo".

7 No original: "cosas que se pudem hacer a gran escala, pero no a una escala inferior, de tal forma extraer nuevas percepciones o crear nueva formas de valor, de tal forma que transforman los mercados, las organizaciones la relaciones entre los ciudadanos y los gobiernos, etc.". 
sempre crescente. A existência desse enorme volume de dados desafia as formas tradicionais de análise e captação, e ao mesmo tempo apresenta novas oportunidades de produzir conhecimento a partir do todo, não mais de uma amostra. Disso resulta, segundo Marques (2017), a emergência de um novo campo interdisciplinar, as humanidades digitais, que incorporam as tecnologias computacionais e algoritmos a pesquisas do campo das humanidades, com possibilidades de acesso a dados históricos e atuais sem precedentes.

As principais características dos Big Data seriam: volume, velocidade e variabilidade (Mostafa, Cruz, \& Amorim, 2015). A primeira característica denota a enorme quantidade de dados, disponíveis em volume crescente - Mayer-Schönberger e Cukier (2013) estimam que a quantidade de dados digitais no planeta seja equivalente a dar hoje a cada pessoa na Terra trezentas vezes a quantidade de informação que se estima que estivesse armazenada na biblioteca de Alexandria -, e a perspectiva de uma abordagem desses dados que não seja feita por amostragem, mas tomando a totalidade.

O processamento dos dados em sua totalidade dispensaria a necessidade de formulações teóricas, na medida em que permitiria obter uma perspectiva total e completa dos fatos tais como são na realidade. No lugar de teorias que explicariam os acontecimentos buscando generalizar resultados a partir de amostras, o processamento dos dados trabalha com a análise da frequência, na busca de padrões, visando obter previsibilidade. Nesse sentido, o Big Data não busca nenhuma explicação do porquê as coisas acontecem, apenas o que acontece, forçando a sociedade a abrir mão de "parte de sua obsessão pela causalidade em troca de meras correlações" (Mayer-Schönberger \& Cukier, 2013, p. 18) ${ }^{8}$ objetivando predições e tendências gerais - mas não exatidão. Trata-se do que Han (2015) chamou de dataísmo, um segundo movimento das luzes que a "tudo deve transformar em dados e em informação" (Han, 2015, p. 67). Para o autor, se no primeiro movimento das luzes a estatística foi vista como um meio capaz de libertar o conhecimento de seu conteúdo mítico a partir de um primado do sujeito, no segundo movimento das luzes, a intenção é "libertar o conhecimento do arbítrio subjetivo" (Han, 2015, p. 67), da intuição, da teoria. Contudo, Essa possibilidade de dispensar a teoria é rechaçada por Han (2015), que ironiza a pretensão de suprimi-la e de lidar com os dados na ausência de pressupostos - ao que ele chama de totalitarismo digital (Han, 2015) - , e por Agostinho (2016), que argumenta que a forma como os dados são vistos e analisados sempre pressupõe uma mediação teórica.

A segunda característica do Big Data, a velocidade, indica não apenas uma propriedade das informações na rede mundial de computadores, de serem acessíveis de forma praticamente imediata, assim como a possibilidade de feedback também imediato a partir de determinados

8 No original: "parte de su obsesión por la causalidad a cambio de meras correlaciones". algoritmos, mas principalmente: (1) a aceleração do crescimento da quantidade de informação disponível, que cresce quatro vezes mais rapidamente do que a economia mundial; (2) a capacidade de processamento dessa informação, que cresce nove vezes mais de pressa (Mayer-Schönberger \& Cukier, 2013); e (3) a aceleração da extração de valor a partir da atividade dos indivíduos no ambiente digital. Juntas essas características produzem um constante e crescente aumento da velocidade e do volume dos dados circulantes. É relevante notar que a identidade entre informação e valor, e a pressão sistêmica para a reprodução ampliada do capital também nessa esfera, é o motor econômico das pressões pelo uso cada vez mais amplo dos Big Data e, ao mesmo tempo, gera pressões monopolistas e tentativas de centralizar a captação e os usos que se faz deles.

Finalmente a variabilidade indica a capacidade da rede de captar as mais sutis variações nas características dos dados e dos usuários do sistema, levantando questões delicadas sobre a privacidade e a transparência com que tais dados são obtidos e divulgados. Ela produz uma ilusão de liberdade por meio do acesso liberado a informações escolhidas de acordo com as inclinações "íntimas" do usuário e, ao mesmo tempo, potencialmente suprime a necessidade de contato com dados incômodos ao usuário, diferentes de suas inclinações.

Parece-nos evidente que as possibilidades de utilizar esses novos dados para produzir conhecimento significativo e útil, como aponta Marques (2017), depende fundamentalmente da natureza da prospecção que se faça em relação a eles, assim como dos fins a que se destina, enquanto, de outro lado, uma utilização do Big Data para intensificar as vendas e a exploração dos usuários, ou para produzir novas formas de controle social mais sutis e abrangentes, tal como aponta Han (2015), se configura uma realidade difícil de negar. Pesquisas realizadas atualmente por psicólogos utilizando os Big Data oferecem um bom exemplo dos riscos que existem para as humanidades digitais ao se apropriarem das ferramentas típicas da atual cultura digital. Elas nos indicam de modo concreto em que sentido a atual cultura digital se aproxima da indústria cultural.

\section{Rastreando comportamentos e traços pessoais}

Em um artigo em que apresenta as possibilidades do uso do Facebook como ferramenta para as ciências sociais, Kosinski, Matz, Gosling, Popov \& Stillwell (2015) argumentam que a utilização desse site permite superar as tradicionais limitações das amostras de participantes das pesquisas em psicologia, acessar as pessoas em um "ambiente natural", fazer cruzamento entre dados pessoais, comportamentais e demográficos com facilidade, uma vez que o site armazena essas informações, entre outras vantagens. Isso porque, como apontam MayerSchönberger e Cukier (2013), no Facebook 
se sobem mais de dez milhões de fotos novas a cada hora. Seus usuários clicam no botão "curtir" ou inserem um comentário quase três mil milhões de vezes diariamente, deixando um rastro digital que a empresa explora para descobrir suas preferências. ${ }^{9}$ (p. 19)

As dificuldades apontadas pelos autores dizem respeito à necessidade de conhecer as interfaces do web design. A justificativa para utilizar sites de redes sociais como o Facebook, ao invés de abordar os participantes no mundo físico, é que atualmente: "uma porção crescente das atividades humanas, como as interações sociais e o entretenimento, comprar e compilar informações, se tornaram mediadas por dispositivos e serviços digitais ${ }^{10}$, (Lambiotte \& Kosinski, 2014, p. 1). Isso permite, segundo os autores, observar os comportamentos de milhões de indivíduos no momento em que acontecem; ao invés de buscar regularidades estatísticas e princípios subjacentes, a análise do Big Data busca simplesmente reconhecer padrões.

O objetivo estabelecido pelos pesquisadores liderados por Kosinski et al. (2015) foi desenvolver uma ferramenta que permitisse prever traços de personalidade a partir das "pegadas digitais" (digital footprint) deixadas pelos usuários do Facebook. Essas informações, fornecidas pelos usuários comuns de forma consentida, mas não deliberada, são armazenadas pelo site compondo um conjunto de dados sobre os perfis, preferências, hábitos etc., que ficam disponíveis para prospecção e utilização por pesquisadores ou publicitários. No caso dos pesquisadores da psicologia, eles se utilizaram de um modelo de personalidade amplamente disseminado e comumente aceito pela comunidade científica norte-americana, denominado five-factor model of personality (FFM), para elaborar um algoritmo capaz de traçar o perfil de personalidade dos usuários dessa rede a partir de suas "curtidas" (Lambiotte \& Kosinski, 2014; Kosinski et al., 2015).

Em "Private traits and attributes are predictable from digital records of human behavior", Kosinski, Stillwell e Graeple (2013) apresentam como rastros deixados por usuários de redes sociais, como suas "curtidas" no Facebook, podem ser utilizados para, de modo automático e acurado - por meio de um modelo de redução de dimensionalidade para pré-processamento de dados de curtidas - predizer uma série de atributos pessoais, como orientação sexual, gênero, visão política, religião, etnia, inteligência, grau de felicidade, uso de substâncias psicoativas etc. Os autores, de modo

9 No original: "se suben más de diez millones de fotos nuevas cada hora. Sus usuarios hacen clic en el botón de 'me gusta' o insertan un comentario casi tres mil millones de veces diarias, dejando un rastro digital que la compañía explota para descubrir sus preferencias".

10 No original: "A growing proportion of human activities, such as social interactions, entertainment, shopping, and gathering information, are now mediated by digital services and devices". astuto, percebem que grande parte das atividades cotidianas hoje são mediadas digitalmente e que esses comportamentos digitalmente mediados ficam registrados na rede e fomentam a emergência das ciências sociais computacionais, lado a lado com o marketing digital. A análise dos dados das redes, sob a perspectiva dos autores, parece ter, ao menos, duas grandes vantagens: (1) dispensa a participação ativa de pessoas para responder questionários; e (2) é capaz de predizer informações que as pessoas desejariam esconder - como idade, gênero e gravidez, por exemplo. Afora a questão ética e de invasão de privacidade que essas "vantagens" compreendem, há um pressuposto mais fundamental a respeito das características individuais e de personalidade que precisa ser revelado.

Por exemplo, o FFM alega representar, por meio de cinco traços, a estrutura fundamental subjacente às variações de comportamento dos seres humanos, oferecendo uma estrutura conceitual que permite unir sob essas características a diversidade das condutas. Os traços descritos pelo modelo são: a) abertura: relacionada à imaginação, criatividade, tolerância, apreciação da cultura, bom senso estético e vinculação política liberal; b) conscienciosidade: tendência a preferir uma vida regrada e minuciosamente prevista, em contraste com uma abertura ao espontâneo e novo; c) extroversão: tendência a ser estimulado pelo mundo exterior, a ser comunicativo e expressar emoções positivas; d) conveniência: tendência a focar em relações sociais positivas, ser amigável, compassivo e cooperativo; e) estabilidade emocional: tendência a não experimentar grandes e bruscas mudanças em emoções (Kosinski et al. 2015).

Esse tipo de teoria de personalidade a partir de traços apresenta um caráter ideológico tanto por ter sido elaborada a partir de pesquisas com sujeitos cujo perfil é denominado, um tanto ironicamente, WEIRD (brancos, educados, integrados ao mercado de trabalho, ricos e democratas) como por ter como premissa um tipo de razão psicométrica que traduz os sujeitos por traços quantitativamente estabelecidos, o que acaba por privilegiar as características que produzem um melhor ajustamento das pessoas a uma sociedade ocidental, capitalista, desenvolvida e reconhecida como uma democracia. Partindo de um cidadão modelo, ajustado, integrado e saudável, os parâmetros tendem a reproduzir e reforçar esse padrão e, por outro lado, a patologizar condutas e perfis alternativos. Esse tipo de critério generalizado incrementa as forças de integração dos sujeitos, confirma a falência do indivíduo e, de outro lado, de uma psicologia capaz de fazer uma crítica de seu objeto.

A ferramenta mais comumente utilizada pelos pesquisadores é denominada myPersonality, e foi desenvolvida por David Stillwell, professor de análise de Big Data e Ciência Social Quantitativa da Escola de Negócios da Universidade de Cambridge. O aplicativo permite que os usuários do Facebook acessem 25 testes 
psicológicos e recebam feedback imediato sobre seus resultados, enquanto podem oferecer voluntariamente seus perfis para pesquisa e compartilhar suas informações íntimas com seus amigos virtuais. Mais de dois milhões de usuários, entre os que fizeram os testes, concederam o uso de seus dados (Kosinski et al., 2015). O Facebook tem um número de identificação para cada um dos participantes e, com o acesso concedido ao pesquisador, é possível observar tanto o tipo de percurso (navegação) realizado como obter dados longitudinais, demográficos etc.

O conjunto de dados acessíveis varia conforme a plataforma amplia ou altera seus parâmetros e políticas. No artigo em que discutem o uso desses dados para pesquisa (Kosinski et al., 2015) os autores informam que estão disponíveis: a) perfis demográficos; b) conteúdos produzidos pelos usuários; c) estrutura das redes sociais dos usuários; d) preferências e atividades mais comuns; e) informações sobre os amigos; f) mensagens privadas. Esse conjunto de informações permite traçar, a partir das pegadas digitais, um perfil do usuário em relação a vários parâmetros comportamentais e demográficos. $\mathrm{O}$ uso desses dados é explicado pelos próprios pesquisadores nos seguintes termos:

Um artigo recente baseado na base de dados do myPersonality, e utilizando métodos relativamente diretos (regressão linear e decomposição de valores singulares) mostrou que os likes do Facebook são altamente capazes de predizer a personalidade e um sem número de outros traços psicológicos e demográficos, como idade, gênero, inteligência, visão religiosa e política e orientação sexual. ${ }^{11}$ (Lambiotte \& Kosinski, 2014, p. 1936).

Resultados similares são possíveis a partir da análise de fragmentos de textos ou postagens feitas pelos usuários, observando variações no uso da linguagem que indicam perfis de idade, gênero e personalidade. Além disso, é crescente a geração de dados digitais a partir das atividades realizadas no mundo físico, pela captação de informações a partir de smartphones, eventualmente utilizando softwares de reconhecimento de voz, ainda que com o desconhecimento do usuário, que tem suas conversas gravadas em momentos aleatórios no decorrer do $\operatorname{dia}^{12}$. Em suma, essa ferramenta permite, nas palavras dos autores, melhorar numerosos produtos e serviços, que seriam oferecidos aos usuários de acordo com seus perfis demográficos, suas preferências sendo continuamente deduzidas a partir dos traços de sua personalidade. A ideia dos autores é que essa ferramenta possibilita

11 No original: "A recent paper based on the myPersonality database and using relatively straightforward methods (singular value decomposition and linear regression) showed that Facebook likes are highly predictive of personality and number of other psychodemographic traits, such as age, gender, intelligence, political and religious views, and sexual orientation".

12 Ver: <https://goo.gl/fRbHRF>. um atendimento mais individualizado ao consumidor, capaz de oferecer a ele exatamente e somente aquilo que seria do seu interesse. Um benefício tanto ao comércio de bens e serviços, que não perde tempo e recursos oferecendo produtos a pessoas não interessadas, quanto ao consumidor, que teria ao seu alcance tudo o que é de seu desejo a partir de suas características únicas e individuais. Mais do que isso,

Ao fim e ao cabo, a Amazon pode recomendar o livro ideal, Google pode indicar a página da web mais relevante, Facebook conhece nossos gostos, e LinkedIn advinha quem conhecemos. As mesmas tecnologias se aplicarão ao diagnóstico de enfermidades, a recomendação de tratamentos, talvez inclusive à identificação de "delinquentes" antes que cometam de fato um delito. ${ }^{13}$ (MayerSchönberger \& Cukier, 2013, p. 24)

Os cuidados éticos imaginados pelos pesquisadores dizem respeito à obtenção de consentimento esclarecido e à informação sobre os usos e finalidades dos dados. Evidentemente, esse tipo de cuidado é inócuo em relação ao sentido que adquire essa prática em relação ao todo, isto é, às pressões sistêmicas que levam usuários a abrirem mão, de um modo ou de outro, de sua privacidade e a serem bombardeados ubiquamente com propaganda, dessa vez dirigida minuciosa e precisamente, a partir de seus perfis de personalidade. Na verdade, esse cuidado parece se relacionar muito mais com a garantia de acesso aos dados sem futuros problemas judiciais, do que com a proteção/preservação de algum direito daqueles que os fornecem - novamente cabe lembrar do já assinalado por Adorno (1994): "o consumidor não é rei, como a indústria cultural gostaria de nos fazer crer” (p. 288). Não parece ser mero acaso o fato de uma ferramenta como o myPersonality ter sido desenvolvida por um professor de uma escola de negócios; a chamada cultura digital se orienta pelo mesmo critério que enfeitiçava a cultura quando Horkheimer e Adorno a denominaram indústria cultural: em tudo o que aparece nas telas da rede de dados digital cintila a forma da mercadoria.

Entretanto, os pesquisadores admitem que o grau de confiabilidade dos resultados, embora atinjam os mesmos níveis de testes aplicados no mundo físico, ainda precisa ser aperfeiçoado para produzir exatamente o efeito de previsibilidade esperado. Na verdade, espera-se um nível de controle sobre os comportamentos sem precedentes na história humana. Sempre que houve algum poder, houve também formas mais ou menos explícitas e eficazes de resistência. Mas, talvez a característica mais

13 No original: "Al fin y al cabo, Amazon puede recomendar el libro ideal, Google puede indicar la página web más relevante, Facebook conoce nuestros gustos, y LinkedIn adivina a quién conocemos. Las mismas tecnologías se aplicarán al diagnóstico de enfermedades, la recomendación de tratamientos, tal vez incluso a la identificación de "delincuentes" antes de que cometan de hecho un delito". 
marcante dessa nova ferramenta seja seu funcionamento sutil e encoberto, especialmente em sua dimensão política.

\section{Big Data como instrumento político}

A pretensão dos defensores da cultura digital de que suas características intrínsecas promoveriam um ambiente de ilimitada liberdade e acesso total ao conjunto das produções culturais humanas se revela, observando os usos que dela fazem aqueles que de fato operam o sistema, um engodo. Muito além do panóptico, desenvolvem-se por meio da rede mundial de computadores e das novas mediações dirigidas por algoritmos e programas novos regimes de vigilância que tornam a privacidade impossível, erodindo as práticas sociais que sustentavam a formação cultural, o que de fato é o principal elemento que permite algum tipo de controle ampliado sobre os comportamentos. Bruno (2013) apresentou a noção de vigilância distribuída na tentativa de responder o que considerou a reinscrição da vigilância no presente, que ainda conta com seus jogos de poder e produção de saberes específicos. Para a autora,

uma complexa rede de saberes sobre o cotidiano dos indivíduos, seus hábitos, comportamentos, preferências, relações sociais, vem se constituindo a partir do monitoramento de dados pessoais, especialmente no ciberespaço. Os conhecimentos que derivam daí têm efeitos de poder que intervêm de forma significativa nas escolhas e ações de indivíduos e populações. (Bruno, 2013, p. 22)

O Big Data, assim como as nuvens onde os grandes dados ficam armazenados, "são motores que impulsionam o capitalismo da informação uma vez que permitem uma forma de saber cada vez mais dominante" 2014, p. 12). Em suma, o Big Data produz um controle cada vez mais preciso e ubíquo que tem a tendência a se expandir aceleradamente, uma vez que o crescimento do capital circulante, no plano da economia capitalista global, se organiza a partir desse imperativo, apesar das constantes e inevitáveis crises.

O controle que se desenvolve a partir dessa forma de saber baseada nos dados massivos, além disso, se configura de forma diferente dos regimes disciplinares que impõe restrições e coerções; agora são os próprios usuários que fornecem as informações, enquanto imaginam obter gratuitamente informações, diversão e lazer, mas trata-se de um jogo assimétrico no qual os usuários não sabem que estão sendo monitorados, não podem escolher quais dados fornecer, e menos ainda o que será feito com suas informações (Cianconi \& Lott, 2016). Segundo Han (2015), a transparência, que se exige de forma sutil e imperativa dos usuários, se converte

14 No original: "son motores que impulsan el capitalismo de la información a la vez que permiten una forma de saber cada vez más dominante". em um dispositivo neoliberal de controle e vigilância totais. Mais informação circulando significa mais capital circulando, uma vez que o sistema opera em função da propaganda. Em suma: ao navegar os usuários produzem informações que têm valor monetário, na medida em que essa informação é capturada pelos operadores do sistema. Estes, por sua vez, organizam tais dados por meio de algoritmos e lucram, mobilizando os usuários a acelerarem seus comportamentos de consumo, seja de bens físicos ou de dados, e a produzirem cada vez mais informações sobre si mesmos, o que permite, em tese, que a propaganda dirigida exerça maior controle.

Nesse sentido, não há novidade em relação à Indústria Cultural descrita por Horkheimer e Adorno. Já a televisão aberta, desde os anos 50 do século passado, produzia programas que tinham a função precípua de manter o olhar da audiência colado à tela, de modo a vender o olhar dos espectadores aos anunciantes. A nova rede global digital tem a mesma intenção, e opera com os mesmos fins, mas a novidade é que agora ela tem conhecimento, a partir dos Big Data fornecidos pelos próprios usuários, dos seus perfis, preferências, gostos e desejos. Assim, desenvolve-se o chamado microtargeting, uma propaganda dirigida a um alvo específico, uma visada precisa do anúncio publicitário em relação às características dos usuários.

Evidentemente, padrões de comportamento e ideias políticas são tanto monitoradas como disseminadas pela mesma estratégia. O'Neil (2017), em Weapons of math destruction: how Big Data increases inequality and threatens democracy, analisa como a criação de programas e algoritmos baseados em modelos subjetivos de resolução de problemas carrega em si os chamados "pontos cegos", que revelam toda uma carga de preconceitos, julgamentos e prioridades de seus próprios criadores, relacionados às suas próprias experiências da vida em sua cultura, seus objetivos e ideologias. Valores e desejos influenciam as escolhas de quais dados coletar e quais perguntas realizar. Os modelos matemáticos que dão base para a coleta dos Big Data são opiniões transformadas em matemática. A grande questão que levantamos aqui é que, na medida em que opiniões, ideologias e preconceitos são transformados em matemática, ganham um grau de confiabilidade e naturalização capaz de suprimir o questionamento sobre o que fornecem, sobre como operam e sobre os efeitos que produzem. Com isso, as próprias opiniões e formas de pensamento são matematizados, incapazes de ir além do modelo que não apenas coleta informações, mas molda percepções e ideologias.

Nesse sentido, a possibilidade do mercado e do Estado confluírem para uma vigilância ubíqua dos consumidores e cidadãos se torna não apenas plausível, mas indicadora do grau de refinamento na administração da sociedade. Além disso, a tendência a uma radicalização da exploração de valor por meio da obtenção e uso dirigido dos dados apaga a diferença entre consumidor e cidadão, reforçando a tendência já existente na época da indústria 
cultural criticada por Adorno de lidar com questões políticas como escolhas de produtos. Se, como indicaram Cianconi e Lott (2016), caminhamos do panóptico para o panspectro, ou seja, para a possibilidade de localização e identificação de todos a qualquer momento, isso se dá com vistas à reprodução do sempre igual. O poder de capilaridade, seja do Estado ou do mercado, que por meio da grande rede e seus serviços on-line e interfaces digitais coletam informações abrangentes, de modo indireto e constante revela uma assimetria da transparência digital correlata à assimetria encontrada por Chamayou (2015) no princípio de uma guerra que substitui a batalha pela caça com drones. No momento em que drones têm o poder de operar em qualquer lugar do mundo a partir de um monitoramento remoto, utilizando justamente algoritmos e vigilância ubíqua para escolher os alvos (Chamayou, 2015), a teoria crítica que quer estar à altura dos desafios da cultura digital precisa considerar radicalmente o significado da abolição da privacidade e, no limite, do sujeito capaz de compreender criticamente a realidade.

É importante levar em conta que a tendência, considerado o motor econômico dos Big Data, é radicalizar a exploração dos usuários, pois já não há aspectos da vida que não possam ser utilizados para gerar valor se ela se conecta todo o tempo a uma rede digital global. Todo o tempo que determinado sujeito passa conectado no mundo digital o expõe à possibilidade de uma exploração ubíqua, na medida em que inevitavelmente ele fornece, produz e faz circular dados e estes são valorizáveis. Assim, se as atividades dos sujeitos se tornam mediadas pela presença de aparatos digitais durante todo o tempo, isso resulta em uma exploração ubíqua, pois de sua atividade se extrai valor ininterruptamente, e isso acelera a exploração e intensifica o controle. A Indústria Cultural da era digital cria condições de exploração ubíqua, radicalizando o aspecto sistêmico da indústria cultural, tal como o vínculo de todo objeto de cultura com a esfera da troca capitalista. Se, à época da escrita da Dialética do esclarecimento, Horkheimer e Adorno (1985) indicavam as tendências na administração da sociedade daquilo que denominaram indústria cultural, hoje, com o desenvolvimento tecnológico digital, assistimos à materialização de uma sociedade plenamente administrada.

\section{Falsas esperanças e perigos reais}

O sonho dos homens de negócios que operam os Big Data é desenvolver algoritmos capazes não somente de prospectar dados significativos sobre os usuários da rede mundial de computadores, mas principalmente prever e controlar o comportamento dessas pessoas e assim produzir o futuro no sentido em que se deseje. Para isso, entretanto, é necessário nada menos do que um esforço contínuo de todas as pessoas envolvidas para agirem como se fossem coisas, anulando as possibilidades de pensar de forma negativa. Isso não é exatamente uma tarefa fácil.
A adesão a modelos comportamentais e a anulação de si mesmo não são conseguidas de uma só vez, e o comportamento fanático dos jitterbugs descrito por Adorno e Simpson (1986) em suas análises da música popular denunciam que sempre há perturbações e dissonâncias que trazem à tona o engodo envolvido no consumo de bens culturais e o esforço necessário ao indivíduo para se sujeitar. A pretensão das grandes corporações no contexto neoliberal é monitorar os comportamentos e continuamente acelerar o consumo, mas isso também esbarra em limites naturais e nas contradições do próprio capitalismo que, em sua crise recente, demonstrou novamente o quão radical é a irracionalidade do todo.

Não obstante, as novas formas de controle são insidiosas justamente porque tendem a atuar silenciosamente, de forma permissiva, oferecendo prazeres e seduzindo os sentidos. O sujeito se sente livre enquanto cede ao canto de sereia da cultura digital. A resistência implica um tipo de ascetismo em relação à sedução da própria imagem coisificada refletida nas propagandas dirigidas, mas também inserção nos meios digitais de modo a quebrar suas pretensões monolíticas. Implica, portanto, ser capaz de significar o mundo a partir de referenciais externos ao ambiente digital e, ao mesmo tempo, tornar-se íntimo de sua linguagem, seus usos e riscos. Tal como na época da Indústria Cultural do século XX, um certo cuidado no uso do ambiente digital é desejável na medida em que preserva o sujeito de ser lançado no turbilhão da aceleração da circulação de dados, mas não há um lugar completamente protegido do alcance dessa nova ordem cultural.

Discussões sobre dinâmicas menos centralizadoras dos fluxos de informação na internet (Parra \& Abdo, 2016) demonstram que é possível pensar não apenas usos alternativos aos que hoje predominam, mas formas de organização diversas desde a estrutura da própria rede, abrindo espaços para a heterogeneidade cultural, para a ressignificação dos próprios Big Data e para o questionamento da vigilância ubíqua. Conhecimento crítico das ferramentas, dos algoritmos e softwares que gerenciam dados também é desejável para compreender e em alguma medida promover alternativas - essa é aposta de Andrew Feenberg e sua Teoria Crítica da Tecnologia.

Para Feenberg (2010), a democratização da sociedade depende de mudanças técnicas radicais apenas alcançáveis na medida em que tivermos voz ativa no processo das decisões técnicas e industriais. Para isso, é imprescindível o conhecimento sobre as escolhas e dos determinantes dos atuais desenhos tecnológicos a chave para compreender tanto sua efetividade, hoje, quanto a base das hegemonias atuais. Na medida em que o desenvolvimento tecnológico é moldado por normas culturais que se originam na multiplicidade da economia, da ideologia, da política, da ciência etc., o desenho e a forma de operar das máquinas refletem os fatores sociais em voga na racionalidade predominante ou, como ele diz, inspirado em Herbert Marcuse, "a política da tecnologia 
depende de aspectos contingentes do design técnico determinado por um projeto de civilização" (Feenberg, 2004, p. 2).

É nesse sentido que Feenberg (2010) defende que os aparatos técnicos, seus desenhos e formas são selecionados a partir de interesses entre muitas configurações possíveis - e por isso passíveis de serem redesenhados, modificados, transformados. O processo de criação e seleção desses desenhos e formas são orientados por códigos sociais advindos das lutas políticas e culturais definidoras de seu horizonte de atuação. Por outro lado, a efetividade e a legitimação da tecnologia são dependentes do estado de consciência/falsa consciência do horizonte político-cultural dentro do qual ela é concebida.

As pretensões de domínio total sobre os homens a partir de um conhecimento sobre seus anseios, desejos, hábitos etc. não é uma pretensão nova. Ela está no âmago do projeto do esclarecimento, tal como denunciaram Horkheimer e Adorno. Essa pretensão nos parece por demais conveniente para os operadores do sistema, que dependem dela para vender seus produtos. Embora seja plausível uma maior eficiência da manipulação por meio do microtargeting, é difícil para os sujeitos afastar completamente da consciência o engodo. O maior problema talvez seja o fechamento cada vez maior da esfera cultural dentro de uma lógica identitária, que tende a se tornar ubíqua e intensificar a exploração. A tendência à aceleração em direção a uma superexploração de todas as esferas da vida, sujeitadas ao imperativo capitalista de produzir mais valor, radicaliza a sensação de fechamento do mundo alienado sobre si mesmo, e pode resultar em ódio e ressentimento cegos, com resultados sociais em alguma medida previsíveis: intensificação da barbárie.

A imersão dos sujeitos no ambiente de uma cultura digital manipulatória, além disso, destitui as subjetividades das mediações que constituem a autorreflexão e a crítica, tornando imprescindível considerar o que decorre da fragilização da subjetividade pelo declínio do pensamento "histórico" (Flusser, 2017) e sua substituição pela lógica da "superfície". O esquematismo sempre foi um serviço prestado aos seus clientes pela indústria cultural: "Para o consumidor, não há nada mais a classificar que não tenha sido antecipado no esquematismo da produção" (Adorno \& Horkheimer, 1985, p. 117), e a utilização de clichês aparece como a saída para uma orientação num mundo caótico por aqueles que, inseridos no processo contínuo de semiformação (Adorno, 1992), são incapazes de reconhecer os processos sociais em voga, mas parecem saber muito bem como agir diante deles. Nesse sentido, ainda são atuais as reflexões de Adorno, Frenkel-Brunswik, Levinson e Sandford (1969) em The authoritarian personality, pois, sem condições de compreender o mundo em um sentido histórico, resta aos sujeitos o ressentimento e o ódio cego a uma sociedade que não se deixa ver, apesar de se mostrar por meio de uma avalanche de imagens. A persistência e o ressurgimento, à luz do dia e sem meias palavras, de discursos xenófobos, machistas, racistas, etc., talvez seja um sintoma significativo da nova configuração da indústria cultural. ${ }^{15}$

Assim, embora seja preocupante a mobilização dos algoritmos para controlar os comportamentos, o mais crítico é a possibilidade sempre recorrente de explosão do ódio cego, da irracionalidade mediada por constelações de afetos destrutivos, culminando na barbárie crua e direta. Para uma teoria crítica da sociedade, a falsa esperança dos novos arautos da razão instrumental e seus novos procedimentos demandam um novo esforço, para novamente desvelar como na dialética do esclarecimento, nesse momento travestido de cultura digital, se manifesta a barbárie hodierna, enquanto ainda sobrevive a esperança de sua superação. Em suma, a sempre recorrente necessidade do progresso técnico em produzir novas formas de manipulação está mais relacionada com sua possibilidade de ruína do que com sua força; fosse a dominação total e garantida, não seria necessário o esforço por parte do sistema, sempre mais qualificado, para manter a todos cada vez mais tecnologicamente integrados. O mito da invencibilidade da tecnologia gera passividade, e o intuito da crítica é justamente o oposto, na medida em que aponta o ainda possível uso da razão para o conhecimento do existente e suas contradições e, a partir daí, para uma reorientação da história - fruto da ação humana - na direção da liberdade.

\section{Big Data, ubiquitous exploitation, and targeted advertising: new facets of the cultural industry}

Abstract: The emergence of the so-called digital culture from the development of new information and communication technologies led to criticisms of the concept of cultural industry, elaborated by Horkheimer and Adorno in the 1940s, defining the new configuration based on interactivity, open communication and greater freedom among users. However, to a critical view, the new configuration is even more totalitarian than the previous one. All the actions of users in the digital environment generate information that can be compiled and organized according to mathematical algorithms, configuring the so-called

15 Han (2016) aponta que é expressiva a diferença entre o homem integrado às tradicionais massas descritas desde Le Bon, e o que ele caracterizou como "enxames digitais" - se nas primeiras deixava-se de ter perfil próprio/individualidade ao participar das multidões, nos enxames há a persistência de "alguém anônimo" pronto a participar de "ondas de indignação" voláteis contra alvos que não ensejam qualquer mudança social, senão a persistência do ódio pelo ódio. A configuração própria às redes sociais digitais instaura uma época de isolamento na qual a sensação de que se pode atacar qualquer alvo estando a salvo sustenta a propagação desenfreada e veloz do pensamento fascista. 
Big Data; such information includes personal preferences, political trends, gender, and even personality profiles, and leads to ubiquitous surveillance and manipulation through targeted advertising, being politically and economically far more effective than in the age of the cultural industry described by Adorno. The update of the critical theory of society implies understanding this new configuration, its pretensions and its contradictions. Therefore, the present article aims both to update the concept of cultural industry denouncing, thus, the new forms of manipulation, and to criticize the idea that freedom is immanent to the Digital Culture, present in its defenders.

Keywords: cultural industry, critical theory of society, Big Data, digital culture.

\section{Big Data, exploration omniprésente et publicité ciblée: nouvelles facettes de l'industrie culturelle}

Résumé: L'émergence de la culture dite numérique du développement des nouvelles technologies de l'information et de la communication a conduit à critiquer le concept d'industrie culturelle élaboré par Horkheimer et Adorno dans les années 1940, définissant la nouvelle configuration de l'interactivité, de la communication ouverte et plus grande liberté parmi les utilisateurs. Cependant, d'un oeil critique, la nouvelle configuration est encore plus totalitaire que la précédente. Toutes les actions des utilisateurs dans l'environnement numérique génèrent des informations qui peuvent être compilées et organisées selon des algorithmes mathématiques, en configurant les Big Data; ces informations comprennent des données sur les préférences, les tendances politiques, le genre et même les profils de personnalité, et mènent à des tentatives de surveillance et de manipulation omniprésentes par des publicités ciblées, politiquement et économiquement beaucoup plus efficaces qu'à l'ère de l'industrie culturelle décrite par Adorno. L'actualisation de la théorie critique de la société implique de comprendre cette nouvelle configuration, ses prétentions et ses contradictions. En ce sens, le présent article vise à la fois à actualiser le concept d'industrie culturelle dénonçant, ainsi, les nouvelles formes de manipulation, et à critiquer l'idée que la liberté est immanente à la culture numérique, présente chez ses défenseurs.

Mots-clés : industrie culturelle, théorie critique de la société, Big Data, culture numérique.

\section{Big Data, explotación ubicua y propaganda dirigida: nuevas facetas de la industria cultural}

Resumen: La emergencia de la llamada cultura digital a partir del desarrollo de nuevas tecnologías de información y comunicación llevó a críticas al concepto de industria cultural elaborado por Horkheimer y Adorno en los años cuarenta del siglo pasado, definiendo la nueva configuración a partir de la interactividad, comunicación abierta y mayor libertad entre los usuarios. Sin embargo, a una mirada crítica, la nueva configuración se revela aún más totalitaria que la anterior. Todas las acciones de los usuarios en el entorno digital generan informaciones que pueden ser compiladas y organizadas de acuerdo con algoritmos matemáticos, configurando el llamado Big Data; estas informaciones incluyen datos sobre preferencias personales, tendencias políticas, género e, incluso, perfiles de personalidad, y llevan a intentos de vigilancia ubicua y manipulación por medio de propaganda dirigida, siendo política y económicamente mucho más eficaz que en la era de la industria cultural descrita por Adorno. La actualización de la teoría crítica de la sociedad implica comprender esta nueva configuración, sus pretensiones y sus contradicciones. En este sentido, el presente artículo objetiva tanto actualizar el concepto de industria cultural denunciando así las nuevas formas de manipulación, como criticar la idea de que la libertad es inmanente a la Cultura Digital, presente en sus defensores.

Palabras clave: industria cultural, teoría crítica de la sociedad, Grandes Datos, cultura digital.

\section{Referências}

Adorno, T. W. (1992). Teoria da semicultura. In Ramos-deOliveira, N. (Org), Quatro textos seletos. Araraquara, SP: Unimep, São Carlos, SP: UFSCar.

Adorno, T. W. (1994). A indústria cultural. In G. Cohn (Org.), Theodor W. Adorno. São Paulo, SP: Ática. (Trabalho original publicado em 1967)

Adorno, T. W., Frenkel-Brunswik, E., Levinson, D. J., \& Sandford, R. N. (1969). The authoritarian personality. New York, NY: WW Norton. (Trabalho original publicado em 1950)
Adorno, T. W., \& Horkheimer, M. (1985). Dialética do esclarecimento: fragmentos filosóficos. Rio de Janeiro, RJ: Zahar. (Trabalho original publicado em 1947)

Adorno, T. W., \& Simpson, G. (1986). Sobre música popular. In G. Cohn (Org.), Theodor Adorno (Coleção Grandes Cientistas Sociais). São Paulo: Ática. (Trabalho original publicado em 1941)

Bruno, F. (2013). Máquinas de ver, modos de ser: vigilância, tecnologia e subjetividade. Porto Alegre, RS: Sulina. 
Chamayou, G. (2015). Teoria do drone (C. Euvaldo, trad.). São Paulo, SP: Cosac Naify.

Cianconi, R. B., \& Lott, Y. M. (2016). Do panopticon ao panspectron: uma reflexão sobre as mediações de poder e a materialidade da informação. Liinc em Revista, 12(2), 243-257. doi: 10.18617/liinc.v12i2.903

Costa, R. (2003). A cultura digital. São Paulo, SP: PubliFolha. Feenberg, A. (2004). Teoria crítica da tecnologia. In Colóquio Internacional Teoria Crítica e Educação. Piracicaba, SP: Universidade Metodista de Piracicaba. Recuperado de https://bit.ly/21kDm6o

Feenberg, A. (2010). Racionalização subversiva: tecnologia, poder e democracia. In R. T. Neder (Org.), A teoria crítica de Andrew Feenberg: racionalização democrática, poder e tecnologia. Brasília, DF: Observatório do Movimento pela Tecnologia Social na América Latina.

Flusser, V. (2017). O mundo codificado: por uma filosofia do design e da comunicação. São Paulo, SP: Ubu.

Han, B. C. (2015). Psicopolitica: neoliberalismo e novas técnicas de poder. Lisboa, Portugal: Relógio D’Água.

Han, B. C. (2016). No enxame: reflexões sobre o digital. Lisboa, Portugal: Relógio D’Água.

Horkheimer, M. (1941). Art and mass culture. Zeitschrift für Sozialforschung: Studies in Philosophy and Social Sciences, 9, 290-304.

Hullot-Kentor, R. (2008). Em que sentido exatamente a indústria cultural não mais existe. In F. A. Durão, A. S. Zuin, \& A. F. Vaz (Orgs.), A indústria cultural hoje (pp. 17-28). São Paulo, SP: Boitempo.

Kosinski, M., Stillwell, D., \& Graepel, T. (2013). Private traits and attributes are predictable from digital records of human behavior. Proceedings of the National Academy of Sciences of United States of America, 110(15), 5802-5805. doi: 10.1073/pnas.1218772110. Epub 2013 Mar 11
Kosinski, M., Matz, S. C., Gosling, S. D., Popov, V., \& Stillwell D. (2015). Facebook as a research tool for the social sciences: opportunities, challenges, ethical considerations, and practical guidelines. American Psychologist, 70(6), 543-56. doi: 10.1037/a0039210

Lambiotte, R., \& Kosinski, M. (2014). Tracking the digital footprints of personality. Proceendings of the IEEE, 102(12), 1934 -1939. doi: 10.1109/JPROC.2014.2359054

Maar, W. L. (2000). A produção da sociedade pela indústria cultural. Olhar, 2(3), 84-107.

Maar, W. L. (2006). O que é política? São Paulo, SP: Brasiliense.

Marques, F. (2017). A realidade que emerge da avalanche de dados. Revista Pesquisa Fapesp, (255), 19-25.

Mayer-Schönberger, V., \& Cukier, K. (2013). Big data: la revolución de los datos masivos. Madrid, España: Turner.

Mosco, V. (2014). La nube: big data em um mundo turbulento. Barcelona, España: Biblioteca Buridán.

Mostafa, S. P., Cruz, D. V. N., \& Amorim, I. S. (2015). Primavera nos dentes: fuga e resistência na era digital. Liinc em Revista, 11(2), 360-374. doi: 10.18617/liinc. v11i2.831

O'Neil, C. (2017). Weapons of math destruction: how Big Data increases inequality and threatens democracy. New York, NY: Broadway Books.

Parra, H. Z. M., \& Abdo, A. H. (2016). Tendências democráticas e autoritárias, arquiteturas distribuídas e centralizadas. Liinc em Revista, 12(2), 334-349. doi: 10.18617/liinc.v12i2.918

Sodré, M. (2010). Antropológica do espelho: uma teoria da comunicação linear e em rede (5a ed.). Petrópolis, RJ: Vozes. 